\title{
INTRODUCTION TO UNDERSTANDING ARABESQUE MOTIFS AND ORNAMENTS USED IN THE MOSQUE IN YAZD
}

\author{
Hamed Hayaty \\ Preceptor of Department of Architecture, Ahvaz Branch, Islamic Azad University, Ahvaz, Iran \\ hamedhayaty@yahoo.com \\ Parisa Adibi \\ Student of Department of Architecture, Ahvaz Branch, Islamic Azad University, Ahvaz, Iran \\ (Graduate Student Islamic Azad Ahvaz) \\ Parisa Pol \\ Student of Department of Architecture, Ahvaz Branch, Islamic Azad University, Ahvaz, Iran \\ (Graduate Student Islamic Azad Ahvaz)
}

\begin{abstract}
The most prominent building in the city of Yazd Mosque can be called. The mosque has a lot of changes throughout history has seen fit your time. In reviewing the mosque, as the Islamic Dygrbnahay faced with various decorations including scrolls, tile and geometric designs. The overall goal of this paper is to study and understand the history of decorative motifs used in different parts of the mosque. According to their importance and analyze the signs and symbols of the painter.
\end{abstract}

Keywords: Decorating, symbolic motifs mosque in Yazd, Islamic architecture

\section{INTRODUCTION}

Decorating has always been one of the pillars of Iranian architecture and its valuation is of particular importance. Brickwork, stucco, tiles, carvings, wood carvings, mirror work and among the decorations that have been more or less prevalent in all courses (Behdad, Jafari 1391). Mosque is the perfect symbol of Persian Islamic architecture and According to Robert Halen brand in Islamic architecture, the mosque, the architectural heart knows the effects of the mysteries of architecture. The use of geometric designs symbolic and philosophical in the sense that enhance a sense of unity to the psychological effect on worshipers in the mosque with complex geometric shapes and repeat proportions associated with these roles creates a sense of order and harmony Yazd Mosque as one of the most prominent buildings in the eighth century with beautiful designs using geometric and arabesque motifs together modulator This is a masterpiece of architecture of the period in Yazd region which features local architecture (schools of Yazd) and common architectural style of that era's style is both Azeri (Hosseini, Abargouei 1393).

Questions to be discussed in this article:

What are the motifs referred to or quoted in Yazd Mosque?

What's important motifs and concepts studied in the mosque?

Iranian art motifs decorations can be divided into three parts:

Scrolls geometric decorations and ornamental plants in this research that is descriptive-analytic method is tried first, a brief history of the Jameh Mosque in Yazd listed and then with library research and observation, arabesque and decorative features of the mosque is examined and analyze and compare the characteristics of each segment designs also according to any debate are examples of related images. 


\section{BACKGROUND RESEARCH}

Mosque of Yazd in the center of the old town and the fence, is located all of it, including the infrastructure that is except of 9800 square meters, the areas decorated with tiles, including scrolls, etc., about 500 square meters. Mosque length 104 m and width of 99 meters Yazd Mosque has seven entries with the entry that numerous roads and alleys associated. Great Mosque of Yazd Over the centuries the building has been built on the remains of variety that in historical texts under the headings city Friday Mosque, the Old Mosque, the old Friday Mosque, New Mosque Vbnahay its accession to the various names mentioned (Khademzadeh, 84: 1384).

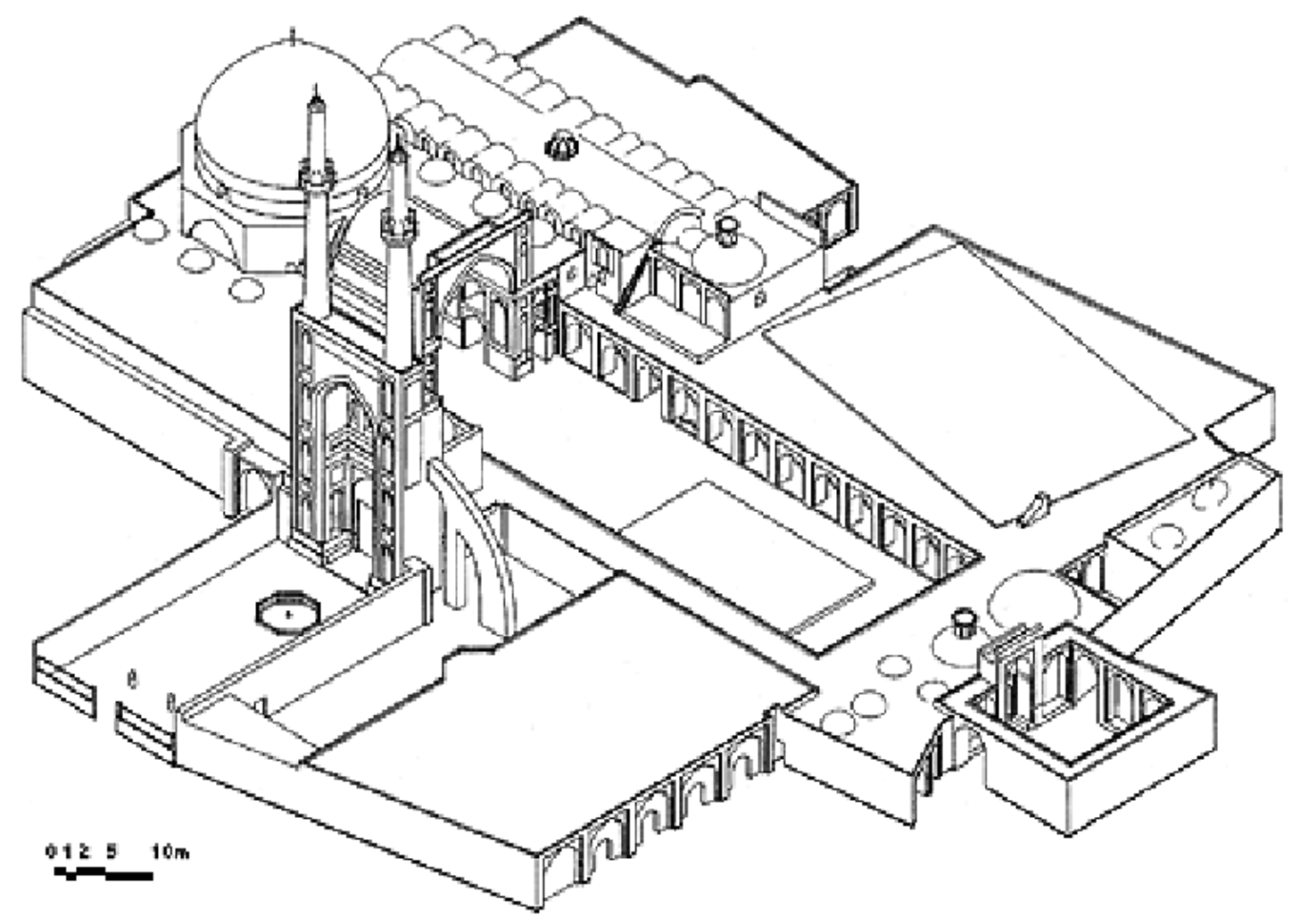

Figure 1. Three-dimensional image of Yazd Mosque

It seems that in pre-Islamic temples in these places have been set up.The first mosque built with the chamber at the time of Mrvlys Safari (Gulshan 536: 1378).In the fifth century zahirodinKakouei to renovate the mosque of Imam Abu Mansur Framrzavlyn (city) that was established in previous centuries.He AldynamyrAlaArsalan Ali Ibn F. and his wife Khatoon mosque minaret beside staged early as the ninth century, has been in place.His son, La'alvlhGushtasp (513-488 BC) Ivan domed mosque with one another and in the West it built near the ancient mosqueZarch coastal canals that are now current in the courtyard of the mosque and the congregation built a house in western $\mathrm{Zl}$ (the 538). Construction halted by the Mongol invasion of Iranand the relative calm in the eighth century that swept Iran began construction speednew Mosque in the base of 724 or $728 \mathrm{AH}$ in the direction of the old mosque of SayyidRukn al-Din Muhammad ibn consistency by Din Mohammad bin system was laid judge HosseiniYazdi.In the Timurid era in the ninth century mosque were many changes and extensions.In the year 809 AH Khwaja Jalal al-Din al-Khwarizmi, coastal dome of the mosque and the house was completely tiled. In 819 AH King Kermani system to the new building was finished Vkashykary mosque inscription Bahaa Adin thousand horse (Al Fatah) Brshn the mosquethe only part of the inscription remains on both sides of the porch.(Khademzadeh 85: 1384).In the reign of Mr. Jamal al-Din Muhammad, known as the Elder J. BrtaqShahtahmasebi main Srdrgah added two minarets above the cupola of the dome Vqbh completed Mqsvrh (Afshar 120: 1374). Afsharieh during the construction of the mosque is no news of actions.But the Zand era inscription dated $1172 \mathrm{AH}$ in Kryas east side of the mosque is that it Vfqnamh of the old mosque is closed(Khademzadeh 86: 
1384).In the Qajar era mosque demolition and renovation range in the series occurred.It measures the reign of Shah Mohammad Vali Mirza in Yazd occurred in the reign of Fath Ali Shah Qajarand
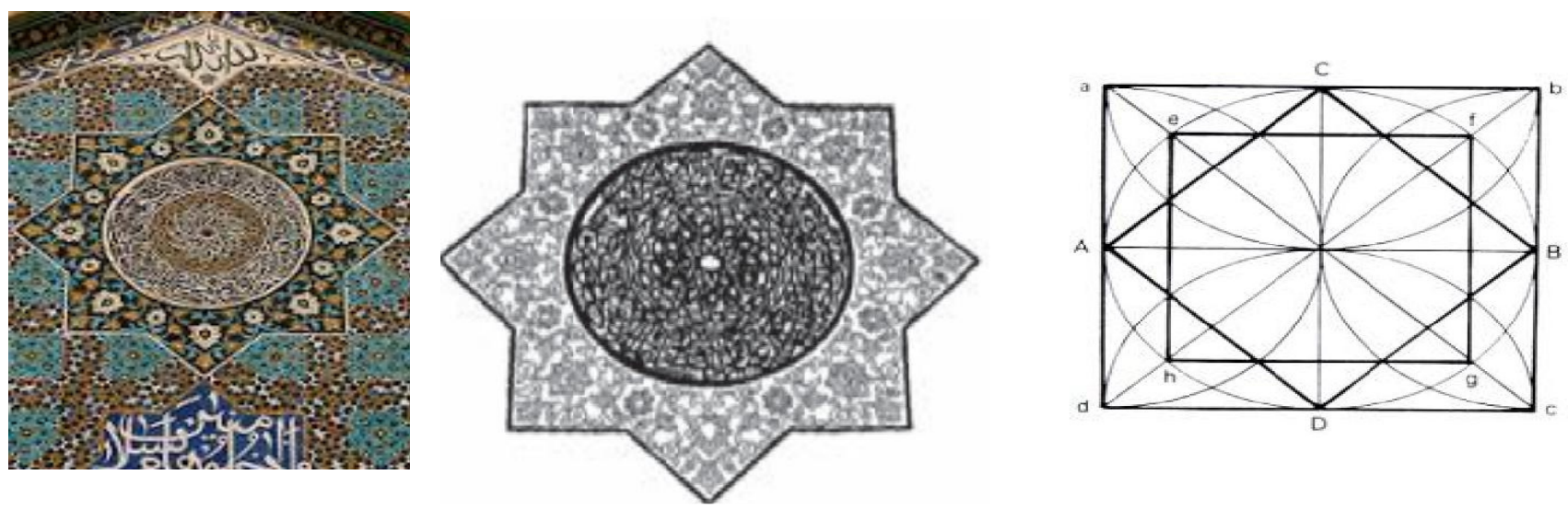

Figure 2 Asly.makhz entrance of eight-pointed stars: Hussein,93:35.

\section{CONSTRUCTION BEGAN}

in 1240. In 1236 he finished (Ibid: 87).Last possessions and restoration of their outstanding appearance and reality mosquerelated to actions by the supporters of the Great Mosque began in 1324 solaractually, this action Haj Seyed Ali Mohammad minister and stimulus of Clergymen in Yazd(Afshar, 122: 1374).

In connection with the Iranian Islamic architecture and decorate it been written books and numerous articles.Including books by IrajAfshar Yazd mementos that in the second volume, the first part of the great mosques of Yazd is famousas well as articles including: Chemical analysis of the symbolic aspects of the ornaments mosque in Yazd, written by Dr. Seyed Hashem HosseiniVhsyn strong cloud janitorial published in the journal of scientific theory,a comparative study of two mosque Tile designs Chaharbagh School and the writings of S. doctor Cyrus Momeni, research in plaster finish bottom of the brick mosque in Yazd approach by Hamid Behdad and BehnamJalaliJafariand other similar articles that are written on the mosque in Yazd and has been used in this study.Now look at the scrolls and other decorations in the mosque there:

\section{SCROLLS}

All Iranian art are closely linked together, and they all expressed a common cultural spirit.Islamic calligraphy art large-scale geometric shape accuracy Byangrsh, led the other arts, the discipline in the team.It is an integral part of the lives of Iranian poetry and philosophy with spiritual light makes all cultural expression and belief.There is a similarity between Poetry and visual motifs.Rhyme and rhythm, intensity and gentle words and songs, wonderful and just completed a long list of headlines, features that can be in any art like them to see.Great art of calligraphy in Iran, such as the Far East and of course the first place.Arabic alphabet that is more decorative aspects of all lines, with a lot of enthusiasm and interest found,with enthusiasm and great interest was developed and Iranians promote it and bring out the astonishing variety of shapes, The architects masterfully combines them in each episode, Azbnay mosque used, as the meaning of the word was God.

These scrolls may be a bunch of long letters,enough to fill an entire wall,inscriptions copies to tiny devices hidden in a spray Mogharnas.By combining them with each other decorative geometric designs hidden role in the victory in the medal or decoration are great.

This post strong authentication has made Aymayat whisper. When reading one of these lines of various other types of reader fails,But worship is not something that accelerates gradually makes its appearance,so that reflections due to conv seems that all the divine message tells the scrolls.

In addition to verbal communication master calligrapher, had an emotional person with a particularly linking, is born out of the abstract line. 
1- inscriptions eastern entrance (main) on the forehead is the new tiled include:

1.1. Name of God Anna FthnaFthaMobinaLak ......Bell Canada's KhbyraTmlvn us.

Truthful Allah al-Azim (to within forty-five inches) in the main port of the third line of tile and white on a blue background.

2.1. The name of Allah the Exalted fireproof per Beaute permission Trf and Yzkr therein the name Ysbh therein crush us LghdValasal (Eleanor / 36)in the forehead and Kufic inscription dated $1370 \mathrm{AH}$ the old Kufic script was created.

3.1 Chapter Friday the third line and forty-five centimeters wide that our environment is Mogharnas vault.

Sura margin between the two.Anna FthnaVsvrh Friday from top to bottom seven pieces arcades Vogel is up and the middle piece Engraving "La ilaha Allah Muhammad Ali but Allah indeed scandalous truth" is.

Scrolls to the eastern parts of the half-arch Rqth you are:

4.1 Shamse of the mosaic inscription on six sides (both sides Tuesday Shamse) and line Vmvrkh of 891 copies each fifty centimeters in diameter Stvdr called them following lines:

The point of view of beauty and glory / Sports embodies the traits of perfection

Always crowded slum of God / heaven Court of Justice Kebria

Hajat prayer for people who are sure / backrest master state religion

Kaaba before Truthfully / ends of arch mosque us

However Arches and porch and the porch of What / Who is to know Kandryn home

To relish the mud ornament / founder of Dell's grace upon grace

5-1-inscription third line width of 819 Vmvrkh fifty centimeters Testament Shah Rukh Khan Bahadur Shah mosaic tiles and the efforts Kermani system installed and the text reads:

"Height Albna'almzm per day prophet, however Monkey King) Adam Zell's whole world of competitive products per midland Bavzh specific argument Haq Bahadur Khan Shah RukhValsltnhDunya parents Khldallh.Glorified fi durable Alzvalaqbal Queen VkhlafthVsltanh truth Muhammad Ali ibnAbiTalib, peace be upon him Messiah Vale AltybynAltahrynVshrVsmanayhTsh per year. "

6.1. Other inscriptions in the previous inscription placed above the Weber Building and Kufic turquoise colors VsfydastAnd when he had shed its old scrolls and the election of Mr. Seyed Mohammad TaghiMostafavi following bits are repeated three times in the inscription:

Hi Kalaf prophet Mohammad / Hi Kalaf Allah (sic)

7-1-text scrolls third line of Mohammad Hakim (the other inscriptions of the mosque Mir flint are in the Eastern time) on the same side of Vmtsl to the following:

"Btvfyq Allah grant him long life Poly however Amara Alkhlaq new Almtaly Sultan Azam gas per time SltnhExtensions Almta Sultans Sultan Al molar binding AladlAlvajb Arab kings ValjmNasra alMuzaffar Sultan JahanHaqValkhlafhValdnya Abbey parents Khldallh Excellence Queen VsltanhLfraz Ali El AlameinAzam Amir Ehsan Malik Akram Hakim al-Adel arguments favor AazmAlamra' Valhkam Al-MusharrafBzyarh Allah's Sacred House of God BnayhMuayyed al-Dawla al-akbar parents Aljajqnbr per Dhu al-Hijjah of the year 861 Ktbh Mohammad al-Hakim. " 
8-1-in the port Mogharnas ten AsmazAsma'bray excellence in Shamse of the tile it 's a new and rapidly ShamseHvallh least another chapter to the complex chain of copies to be seen, as well as (Allhmhmd Ali) in Kufic.

9-1-inscription on the medallion and over twelve Imam Ali MahmoudiDerbenaskhi action Mehrizi architect and historian of the lunar year 1365 is in VmnarHarahdhDarbvdh.

10-1-look at both sides of the niche or arcades to the altar there is mosaic tile that Srasrazand inside each square with lines Kofi seen three goals Babarat Alhamdulillah (four) al-Allah (four), Allah Molk (four) and two parties to the potential role of Allah (on the right) Valz·h Allah (on the left).

11-1-on the sides of both sides of the niche named Mohammad Ali in Kufic among the flowers and bushes Decorative mosaic tile is repeated.

12-1-over the two Shamse very nice niche with mosaic tiles is that they are in Kufic "Yasltan or Glory" is repeated.

13-1-in period in the view of the altar: "The al-RahmaAlzyfAlmhtaj to Allah ...... (name deleted) Ben Mahmoud Haji Taj al-Din KdvkAlbta'" (Afshar 127: 1374).
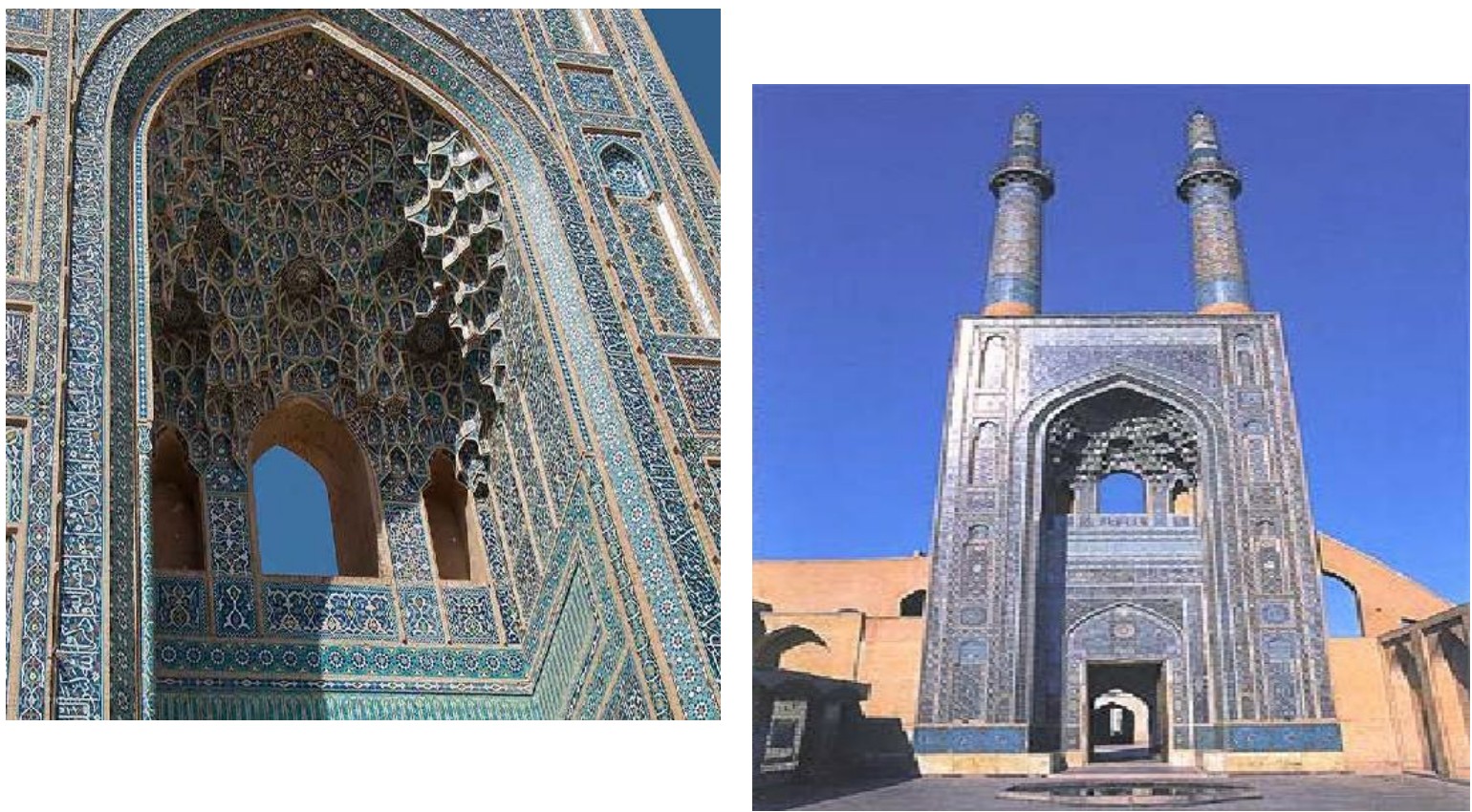

Figure 3.srdr Asly.makhz: Gallery of Architecture and Interior Design

\section{2. atrium (Kryas) - the main altar}

1-2-in the under-roof blue-line inscription dated 777 copies Brgch is good, but unfortunately it has come to abrasion and damage Yazd Amir Shams al-Din Muhammad, according to the new record after the inscription records the building atrium.

Neyshabur is an ode Ktbh text of Hassan speaker informed that the first line of the "HP Kaltaf HP Almmjd And writing on it" ....Thryrafy Lupine year and Sabin and SbmayhHjryhAlnbvyh. "(Afshar 129: 1374). 
The main altar or sanctuary in a dome home, decorated with mosaic tile and brick inscriptions and percussionist and two star-shaped tiles appointed in the name of the craftsman and construction on the altar is closed.

In the sanctuary of the mosque, part of a small tile in the shape of the planet and of all colors used in the tiles of the mosque was used. (Dehghanbanadaki, 1387 Mehr news agency).
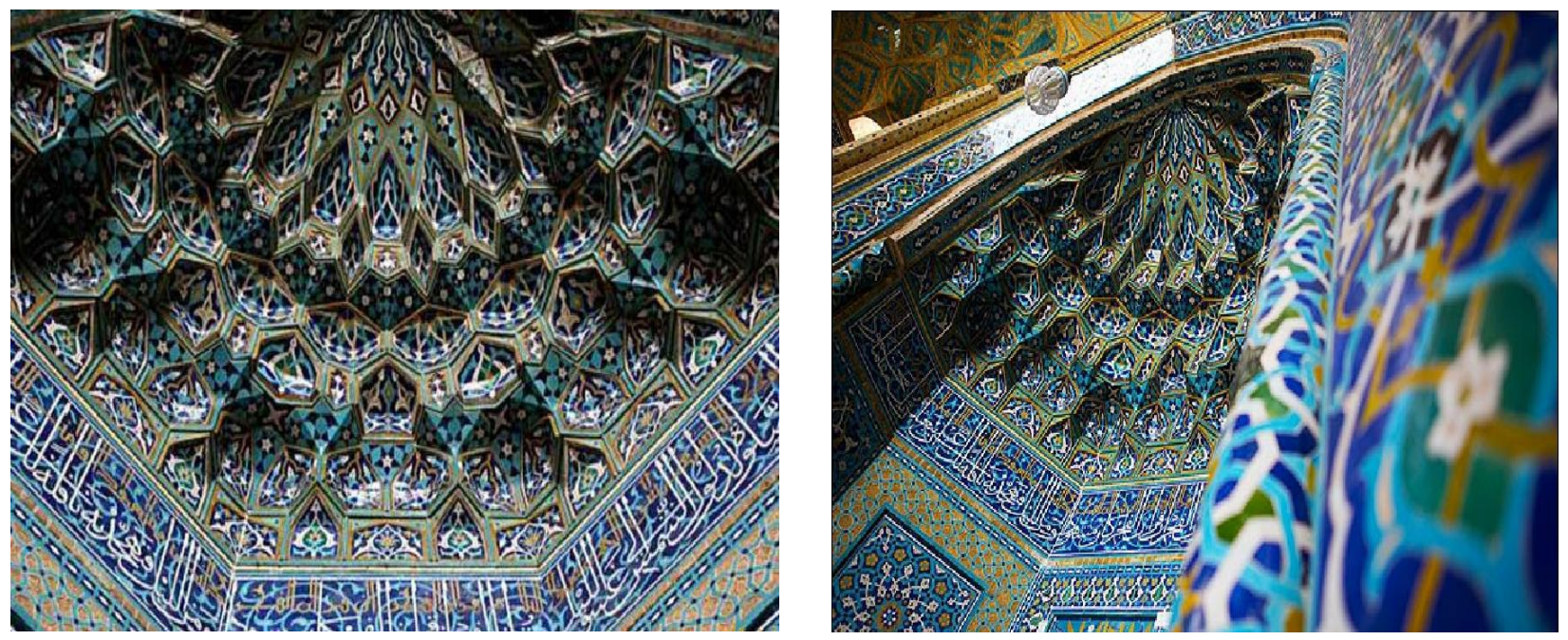

Figure 4: Inscriptions and decoration of the altar in the form of tiles Mrq.makhz: Gallery of Architecture and Interior Design

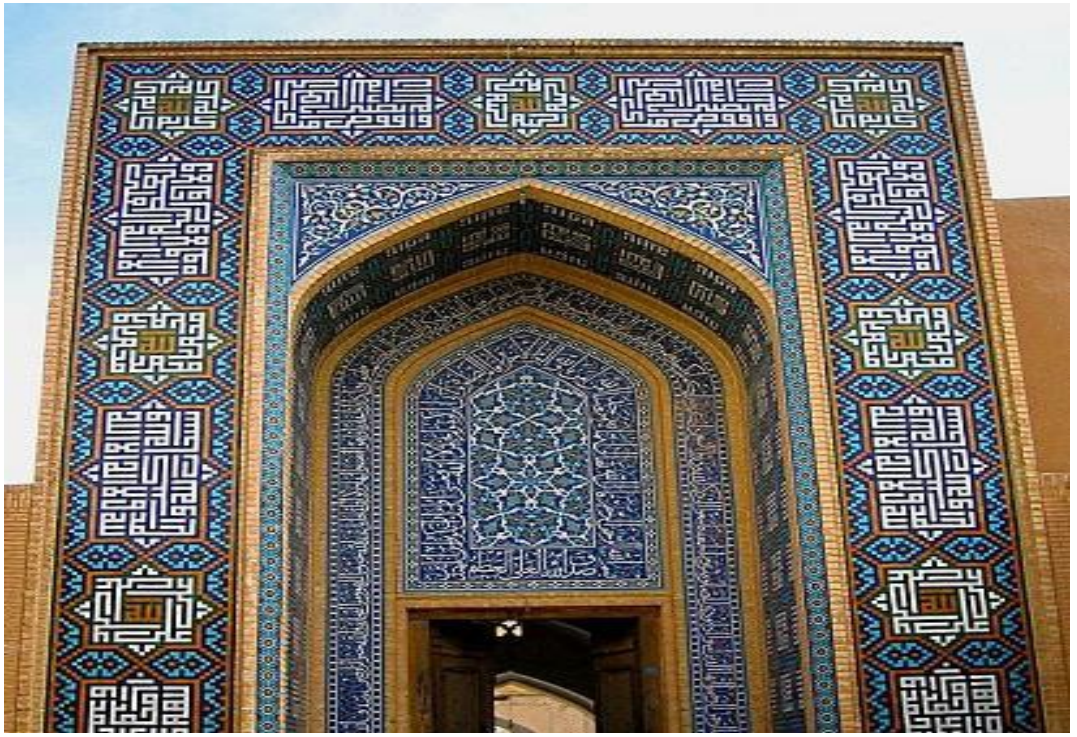

Figure 5.Atrium (Kryas) .makhz: Gallery of Architecture and Interior Design

\section{3-Manar}

The Manar the mosque at the behest Qajmal Jamal al-Din Muhammad is known to most at the Ministry of Yazd he was held responsible Tahmasp and was rebuilt in 1313. Cal of the Earth's surface is approximately fifty meters tall minarets of the local environment to which they are Drkafy eight meters. Names of Allah and the Quran body and sticky tiles has been in that role, as follows:

1-3- "In the name of God Almighty AlzyEsriBbdh ....

"Ho AlsmyBasir."(Between Israel) to the third line below the shelf. 
2.3 "bath Ykad" Kufic and blue tiles on white background.

3.3 In the context of Minar Muhammad Ali Kufi repeated.

4-3 in the bottom of the "Name of God" in Kufi "

5.3 The-shelf "Allahu Akbar Allah much" in the third line is repeated.

One of the minarets are two ways that one way to climb and to come back the other way. (Ibid. 144)

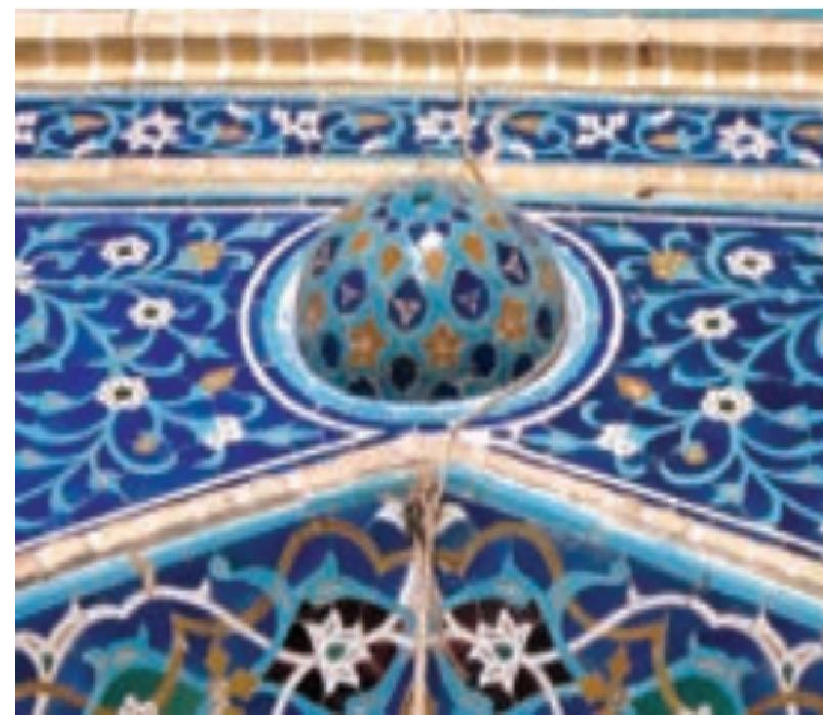

Figure 5.The high altar globular Source: Hosseini,93:38.

4. bedchambers

East Nave (toe) in 777 on the orders of Shah Yahya Mozaffari. In the upper part of the sanctuary have made it work Vmqrns Azgch. On the altar eight pieces of mosaic tiles (size 30 x $35 \mathrm{~cm}$ ) rectangle at the lower edge of the mosaic tiles to size $58 * 108$ installed the role of the diaper Vbart "God VhvFsykfykhmAlsmyAllym" complex and very beautiful for the decorations and combined.

Thirty-eight meters length and width of Western yard is nine meters high and the windows network and King emirates plinth is made of tiles Timurid era.The bedchamber was built during the reign of Amir Ghias, according to Mr. Seyed Ali Mohammad minister until recently called "Ghyasyh" is known. 


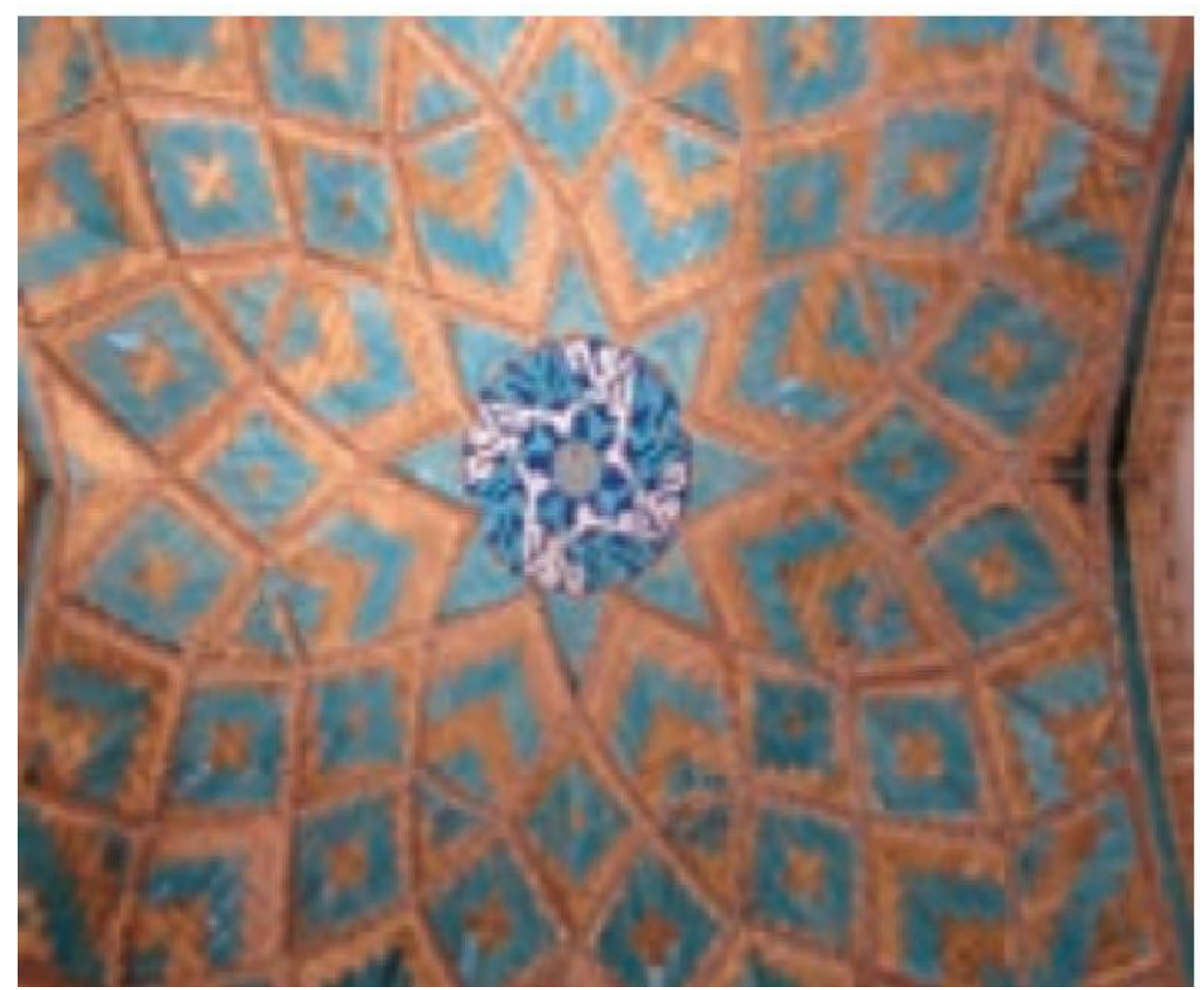

Figure 7.Star-shaped ornaments under the roof of the atrium leading to the dome, Source: same

Prince yard length to width twenty cubits thirty-seven Western King in the North Courtyard by Prince Mohammed, but Mirza was built in 1240 Lunar .daray forty-eight columns (ibid., 146).

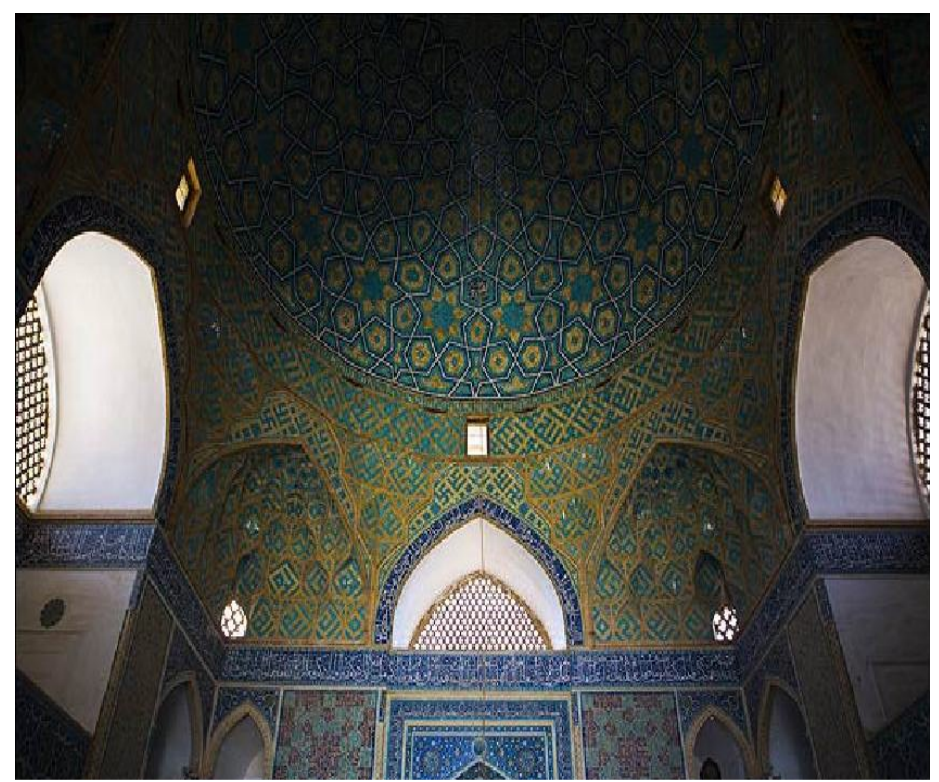

Figure 8.Western yard, Source: Gallery of Architecture and Interior Design 


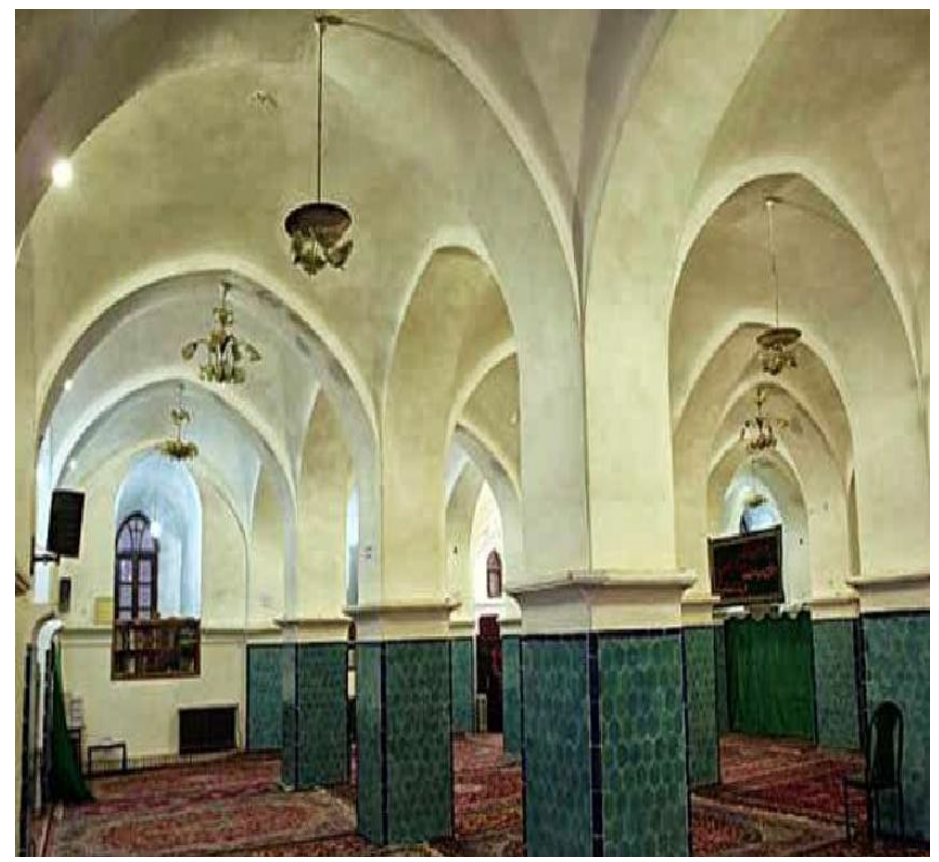

Figure 9.Prince yard, Source: Gallery of Architecture and Interior Design

\section{5-Ivan Home}

Ivan's length thirty meter and width from the beginning to the altar fourteen meters.

The works are part of the mosque can be seen from the outside to the inside is:

1-5 inscription in the mosaic tiles and the line manuscript vault, twelve Imams.

2-5 in the top of the columns of the entrance two sides square Kufic script and the words "ol Allah" is installed.

3-5-tile mosaic inscription manuscript line on top of the column with the words:

Right hand, "Faye Sultan Bahadur Shah ZemanAlstlanAlazm parents Khld certain ValkhlafhHaq Allah Tlay Queen Vsltnh Fi Al-Alam".

Left hand "La'almbanyAmrtbaTvfyqa grace of Allah AlhamyChqmaq together with Amir Rasul Fatima bint al-Shami Smyth AlbtvlFtqblha receptive Hassan per city (sic) the year 0836".

4-5-The following columns on both sides of the porch of stone Mrmrst And on each line versions of "Jlvabalslvh before Alamut" is engraved.

5-5-since the beginning of the curved roof patio door from the right side of the inscription good repealed the chapter "Fatah" and in the yard away from the start and all was right-hand side.But the rest of the yard is not something from the "lemma directly latter" to "YjbAlzra" that leads to the opposite side.

This book is, so that in this new date is recorded Yazd is Karbha'aldynHzarsp that the Calligraphy manuscript of his time. In particular, he mentioned that more useful information to briefly quote:

"Maulana his holy age at the time of Eighty aggressors Bvd.thdNmvd.dr effect that night in a dream world to serve the majority of the prophets ....he ordered him to write his last overlooking BOOK sudden weakness within sight Vrsh hand carved pen to pen in his hand he found compassion income Frmvdnd.chvn sleep ... " 
6-5-over porch roof to Kufi inscription are the names of God in the form of imitation and plaid.

7-5-The remarkable Vhnrmndanh the general tide of two pieces of mosaic tiling mingle with brick percussionist with the flowers on the altar also used Vbth that look alike (Afshar, 147: 1374).

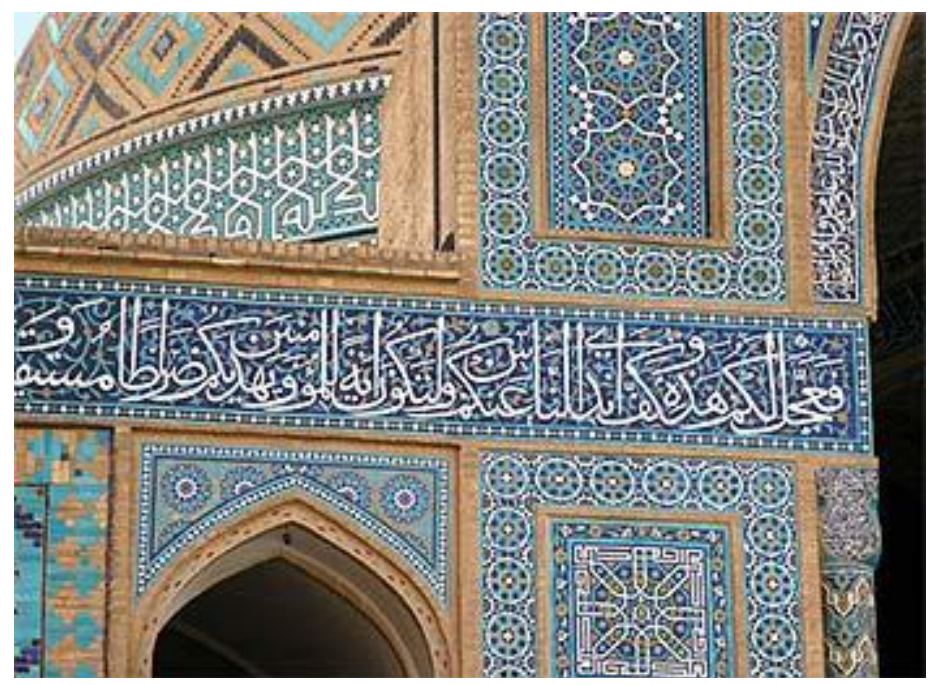

Figure 10.Calligraphic manuscripts of verse 20 of Surah Fatah, the effect of BahaHezarAsb Source: Gallery of Architecture and Interior Design

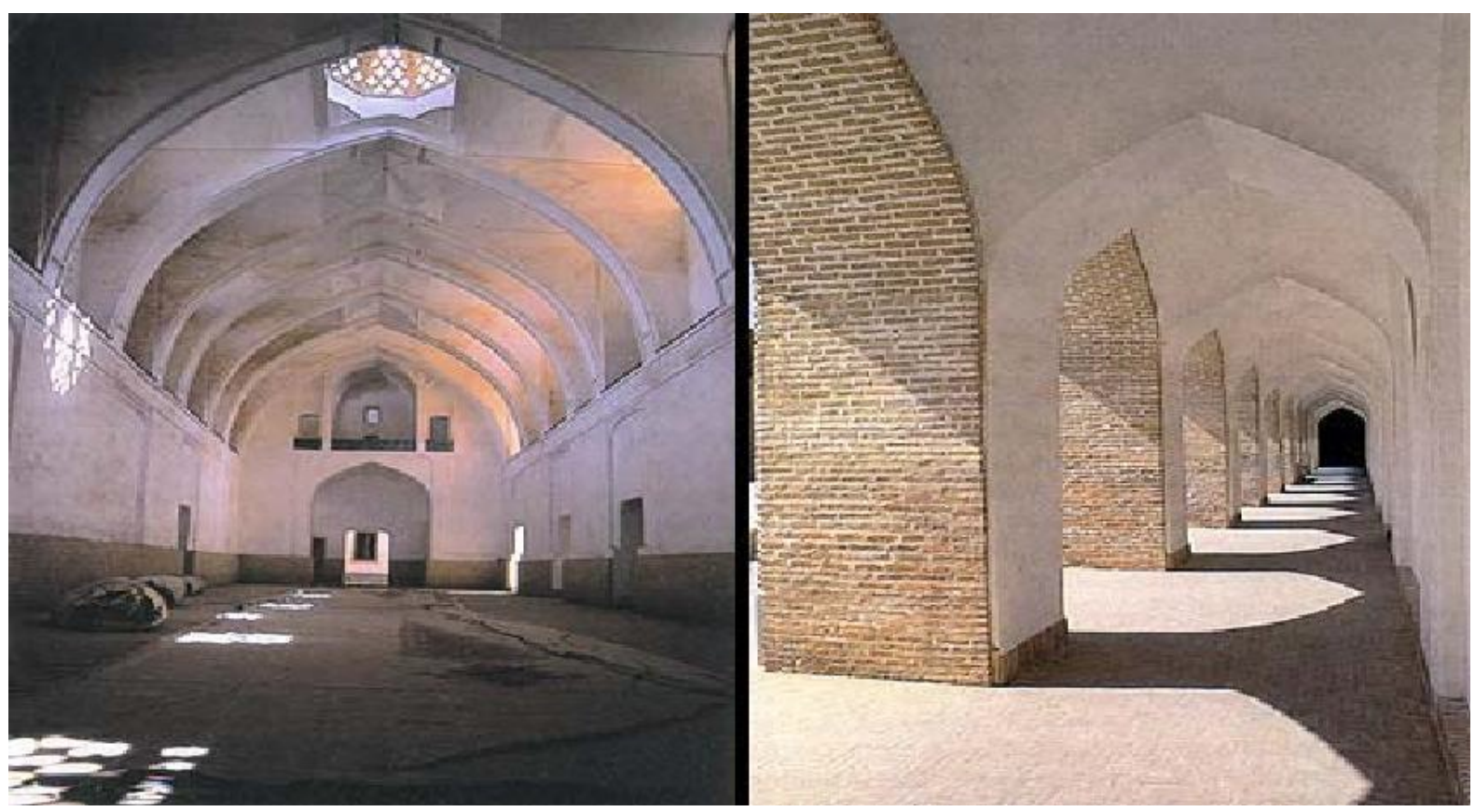

Figure 11.Mirza Vali Muhammad porch, porch Ghiyasuddin, source: Wikipedia Shi

\section{6-Dome}

1-6-in the vault of the dome and connected to warping of the chapter Alasry inscription is in line versions.

2-6- soffit Kufi and turquoise tiles Allahu Akbar repeated.

3.6 In Mogharnas "Muhammad", "Ali" is repeated. 
4-6-under earrings "Allahu Akbar" Kofi repeated.

6.6 on the eastern and western walls Under the Dome "Allah", "Muhammad" is the tile and Kufi inscriptions.

7-6-northern and southern walls with tile Vkvfy foundation "Allah Akbar Sobhan Allah Valhmdllh Vela Velailahailla Allah, Muhammad is the Messenger of Allah Allah" is the inscription.

8-6-in the top of the altar on both sides of two clover-shaped flowers of mosaic tile installationwithin the four "Ali" and "The Name of God - ShhdallhHenin La IlahaKhyralrazqyn" role is.

9-6-in the frontal altar "AqmAlslvh prayers ........spots" in Kufic, Venice "AqmAlslvh ......Mhmvda authorities "manuscript line, and" La ilaha Muhammad Ali, but Ali Hqahqa "manuscript line coarse, and" Dvazzh Imam "fine manuscript line with the" inscription perfection "is the inscription.

10-6- two columns on the altar inside the two-goal edge inscription of ten centimeters in diameter octagonal mosaic tiles and there naskhiThe result: the right, Haji Din Muhammad ibn Abi Bakr bin Al YrfBvaladalyzdy action.

Left hand, fi themes of MoharramLsnh Lupine and Sabin AlhjryhVsbmayh.

11-6-part of the decorations inside the sanctuary mixture of delicate mosaic tile bricks multiplicative effect Province.

12-6- travel corridor on both sides of the road there is a subtle grid of tiles(For women who wanted to oust the congregation of men, for him to come to the question of Imam mosque) on top of two inscriptions copies of mosaic tile installation.

Right hand, fireproof Allah: and Allah Alhkm of La Ilaha Ho Beneficent the Merciful.

One Almsajd Allah Almighty Allah fireproof left hand Fela'sTdva with Azim true authorship.

13-6- dome ceilings role of geometric shapes of the tiles embedded in one of those named in the previous Gnbdst dome figure is as follows:

"Saadbin Mohammed al-action pass AnbnaYazdi"

14-6-on the bottom floor under the dome Jzrhay Shamse and bergamot and very beautiful flowers that the design of geometric and floral patterns and to attract the mosaic tile. (Afshar, 150: 1374). 


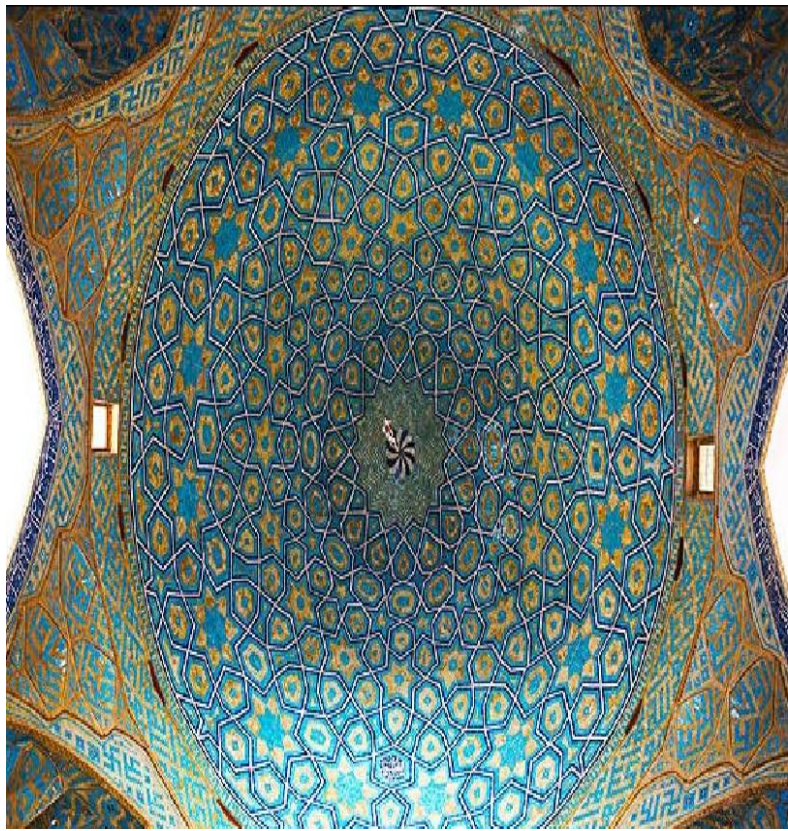

Figure 12.Decorating under the dome, Source: Gallery of Architecture and Interior Design

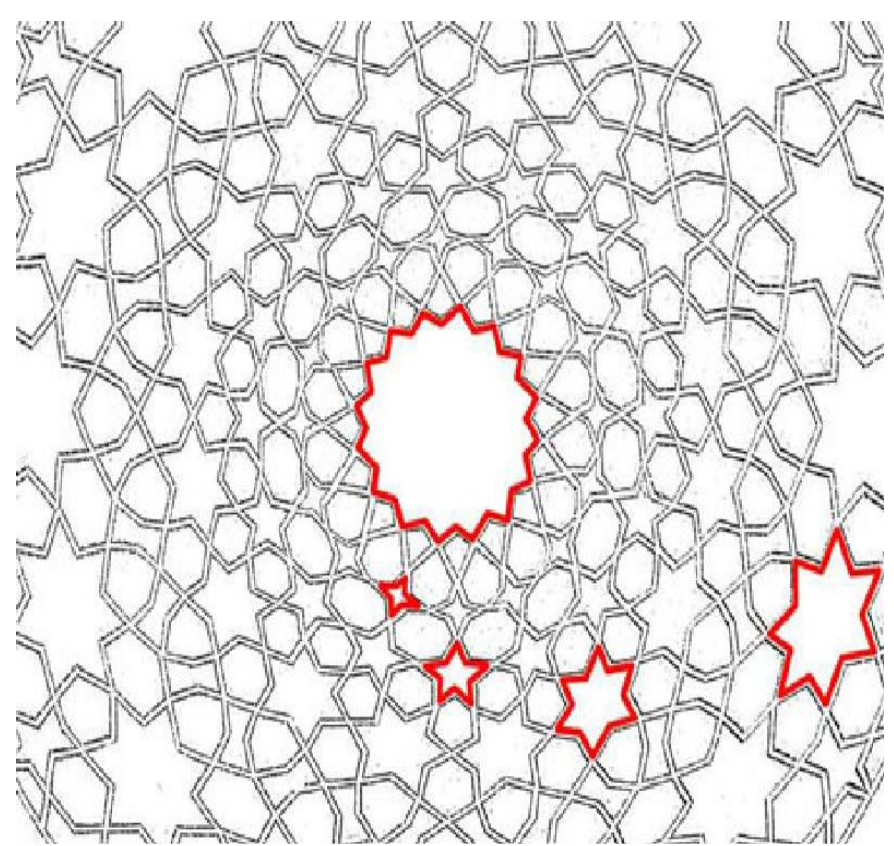

Figure 13. Shamse constituent nodes battalion of hands under the dome, Source: Kasraie

\section{GEOMETRIC ORNAMENTS}

Art Bench is a nation that has always mixed art with life, your taste often living in building the needed equipment is used and therefore that Iranian art is often decorative.

Iran's decorative arts such as humans, animals, plants, landscapes and nature or parts of them have been Vbkar, but because the wood can not work in textiles and ceramic tiles, as presently should be similar to the nature Ramraat, Iranian artists at the beginning and the initial stages, art motifs preferred motifs of nature summary and next steps are, Including those of Turkmen carpets of sun and stars, instead of the sun often put eight corner and Sun are decorated with various colors and vertical linesOr stars that are left on the sidelines, much like it does in fact are not real star.

\section{SHAMSE AND STAR MOTIFS}

Shamse is a symbol of diversity in unity and unity in diversity. In this role has emerged that forms the center of Sateh have been great. The role of light evokes the concept of the names of God. (Stari 1376: 53).

\section{PENTAGRAM}

Cinque and the five senses of human beings usually know dd five in the Islamic tradition is important.Five people of the cloak, the five pillars of Islam, the Prophet arch five .... 


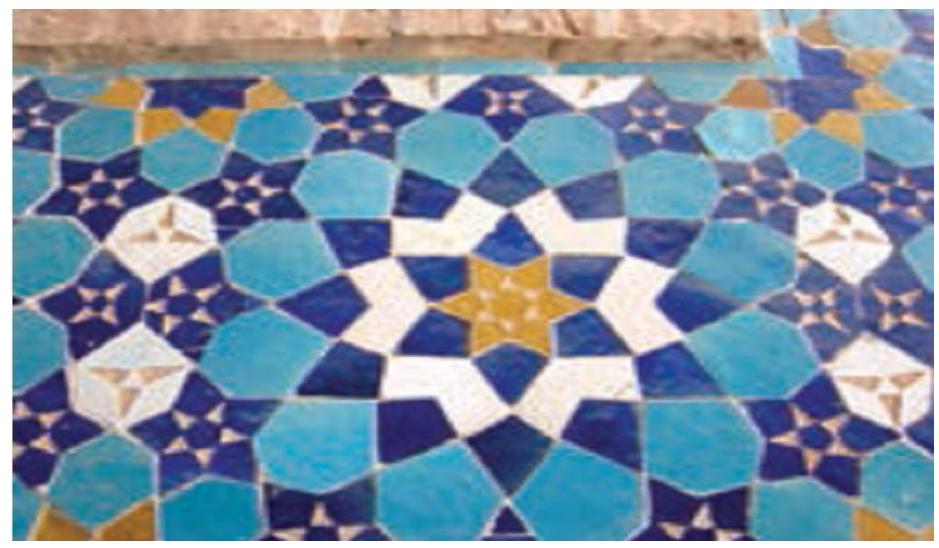

Inside the dome mosque in Yazd Vbsvrt bar fringe motifs of stars and Shamse have to just nested roleand all the walls of the south porch of the dome is home for work tape.Shamse on the sidelines of a dozen full, five-pointed stars have been involved in large numbers.

\section{EIGHT-POINTED STARS}

Most of the motifs used in Yazd Mosque has been working for eight-pointed starsincluding the role that the fifth-sixth cent rosette flowers. Eight-p Figure 14.Shamse and five-pointed star motifs, Source: Hosseini,93:36.

stars of rotation of two squares in both emerged from the long number eight, number-coded acted sun.And in Islam as "eight paradise" "eight eight doors of Paradise" is expressed (Imam 63: 1381).Part of the eight-pointed star motifs used in the Mosque of Yazd Mosque in the eastern seen Drpyshany head.

(Figure 1) in the center of the two circles a star that is nested within it there are inscriptions in third.On the sidelines of the stars arabesque beauty and fawn with white flowers and foliage color blue mosaic tiles can be seen (Hussain, 37: 93).

\section{THE STAR-FILLED}

In the book known as the Ikhwan al-Safa officials conduct ten times for every time there are ten features.Ten return to show unity.Because the first step is to export starts a new plurality.The mystical one and ten are the same as hundreds of thousands (Barati 78: 1380).

\section{SHAMSE TWELVE FULL}

Twelve full twelve Shamse used in this Shamse can be attributed to the vision of the architect Twelver Shia.In fact, this number is important in terms of Astronomy fancy funeral.

A full twelve Shamse south porch on the inner wall (dome) and the walls have been left at the bottom.

Shamse on the grounds that the walls have been covered with turquoise blue hexagonal tiles curved radius is Shamse.Curves consisting of two strips of ultramarine blue (bold) and is rusty. Shamse itself is shaped like a sunflower. 


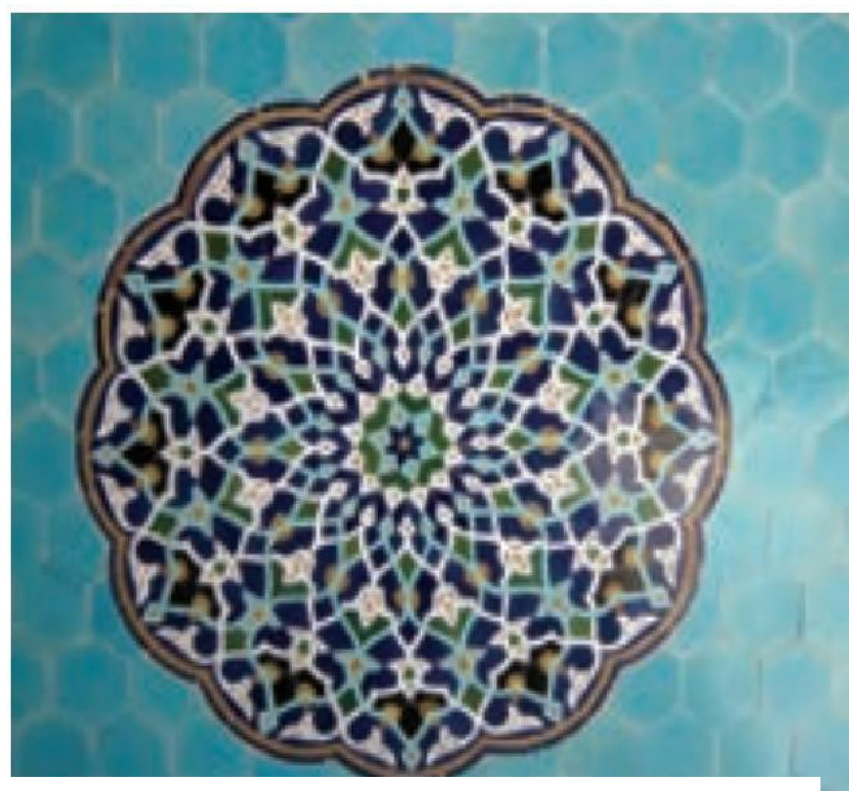

Figure 15. Shamse the full twelve used in domes, houses, Source: same

Another dozen Shamse used to fill in the mosque in a box Square Garden is located in the south walltile mosaic print and fringes around the map with white beading.At the center of this role is a full twelve Shamse inside which is decorated with arabesque stucco.

At the center of a flower arabesque (star) eight can be seen that in the end leads to arabesque. Outline the role of a Chinese knot work.

\section{SEVENTY-TWO FULL SHAMSE}

Shamse used in the largest mosque in Yazd on both sides of the main (east) is closed.This Shamse has a radius of seventy-two golden. In Shi'ism number of martyrs of Karbala 7272 reminiscent of Shamse can somehow this symbol is reminiscent of the Battle of Karbala.This Shamse within a rectangular box Varasth the arabesque is located in the center of the Name of Allah, Muhammad Ali is closed.

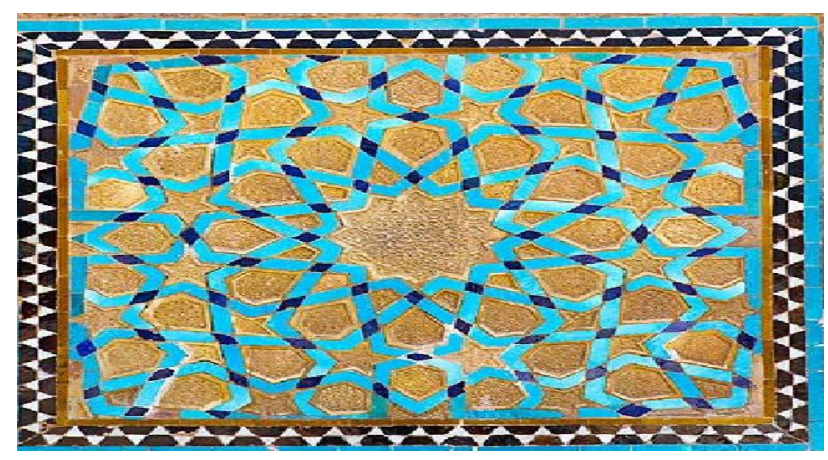

Figure 16.Seventy-two full entrance Shamse Source: same 


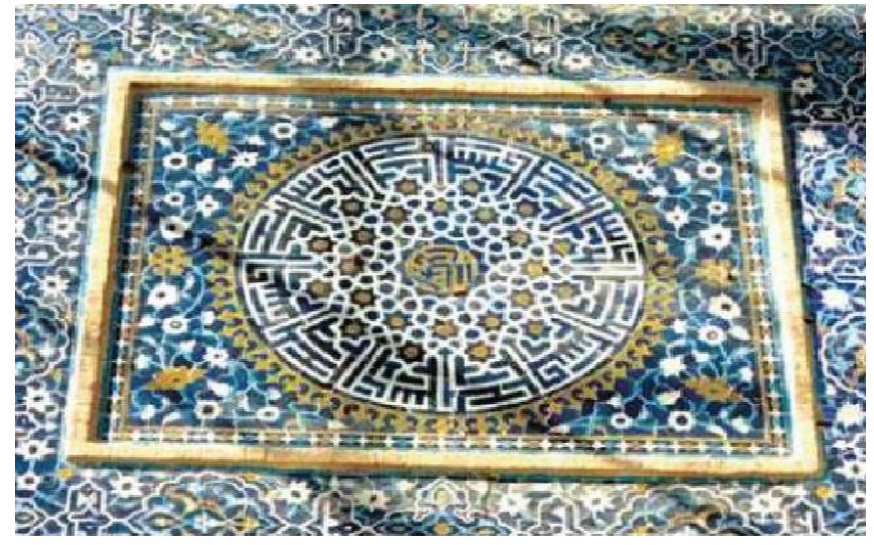

Figure 17.Shamse south wall with twelve gates, source: same

\section{CRESSET}

Icicle lights as well as niche means that the ceiling be nailed (Dehkhoda: under "Icicle").Kandil role of the first century $\mathrm{AD}$, appeared on the stone altarand after a while the tombstones and altar were also involved tiles (Danesh-Yazdi, 73: 1387).As its name Brnyayd this element is linked to a bright light.In simile Quran SatehNyznvry to the entire world and all things in the universe particles that constantly stream in the form of grace and mercy."Heavens Valarz Allah Noor" (Light: 64).

Kandil role Yazd mosque in the middle of a stone Mrmrmhrab like to be seen predominantly in the South porch.As of motifs suggests, lanterns among an altar by a chain of eight loop is hung from the ceiling. This is bowl-shaped stalactites form. On body work and its role includes diamond that is a decorative bar in the center of each of them is located on the circular Jstgy.It seems that the upper part of Kandil around the edges of the grooves.

Because the Shiites in the south porch to guide the light that is the worship of One God.
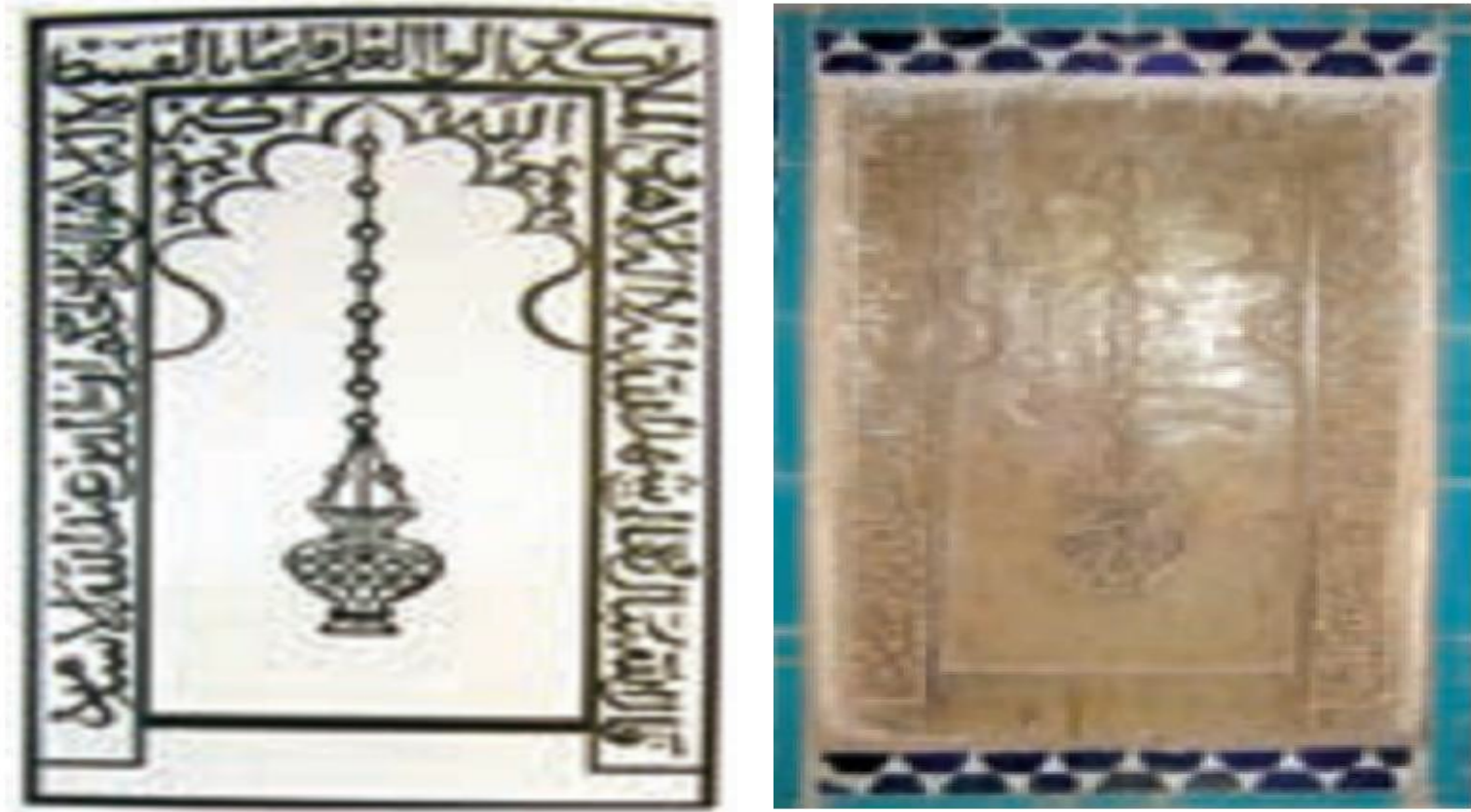

Figure 18.Kandil role Predominantly south porch, Source: Danesh-Yazdi,159:1387

\section{ALTAR MOTIFS}


Modify the altar of Islam among the Arabs, there is much more. The word comes from the verb HarbHarbMsdrshVmhrabh taken that thought to person to person, the war between the two are Vshmny is Aftayh (Sajjad, 50: 1375).

In verse 13 of Surah Saba Tabatabai wrote: "The word which means Nmazgah Mharyb the altar and place of worship, word Tmasyl the image that is meant to mosque every Chyzast" (Tabatabai, 260: $1363)$.

According to the above meanings, use of the role of Yazd Jame Mosque in relation to the place of worshipand a symbol of the pious before God, because the majority of altar designs have been used as a mosque in the southern balcony and, as mentioned, South Avon Vbadt is the most important place for prayer.On the south porch attached to the wall are two columns façade is decorated with mosaic tiling.Arabesque motifs like an altar that just work.

Designs for four distinct colors white turquoise blue water of La Jordi Vhnayy that the usual color all the tiles of the mosque. This role will have rows and all levels are the views (Fig. 19).

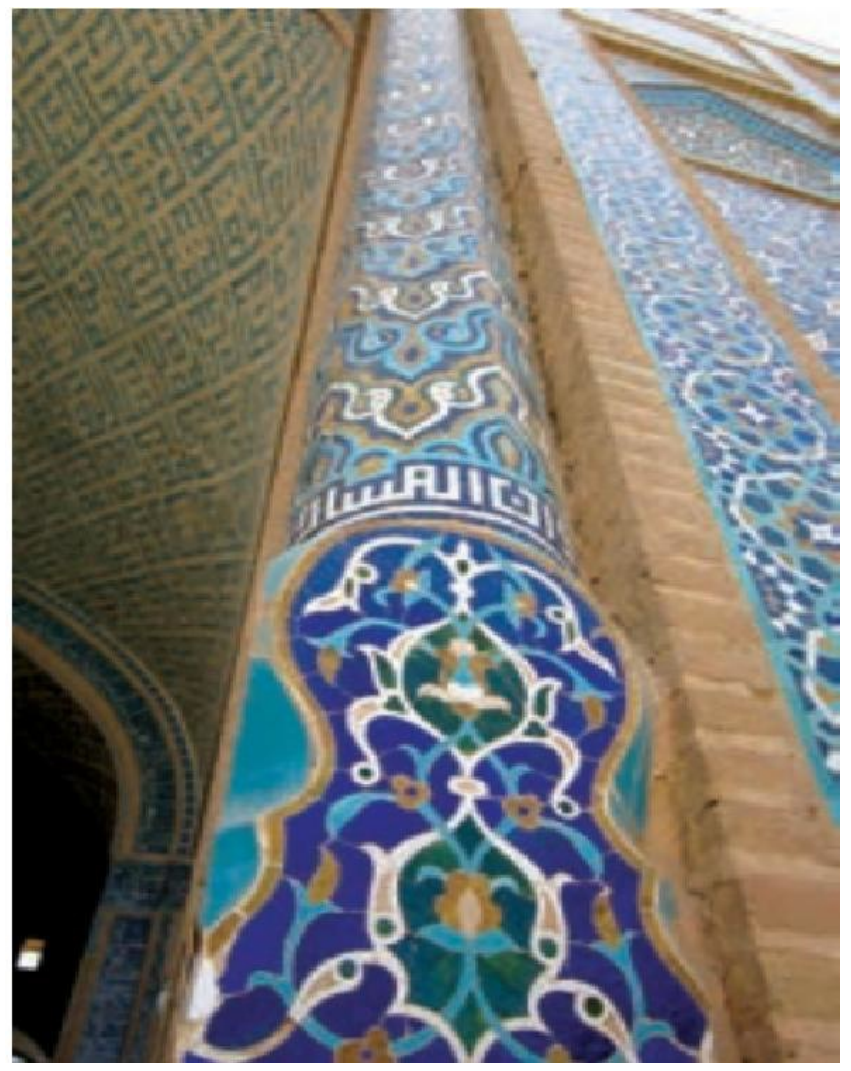

Figure 19.South porch altar motifs such as decorative half-columns, Source: Hosseini, $93: 40$

\section{CONCLUSION}

Throughout history, always between art and spiritual traditions derived from religion is very closely there.Art is the most important manifestation Shiite mosquebecause the local mosque for worship masses were considered, as well as the political meaning is quite obvious.In other words Mosque confluence of three elements: politics, religion Vtlqat orientation of the masses.

Mosque in Yazd motifs Shamse and star motifs, as Qandil, altar-like motifs, stucco motifs chain, etc. that make up the motifs used ShamseVstarh most designs. Shamse symbol of diversity in unity and unity in diversity and diversity is an expression of God's attributes.

It is important motifs used in mosqueWhich is considering the establishment of a central government Sunni discussed at the time of making the designs builders and founders of a religious Shiite thought 
the show. Some of these geometric designs such as Shamse 72 Vaslymy the entrance dome home, index-images used in Yazd Mosque that other buildings from the era of greatness and the beauty can not be found. The motifs in terms of aesthetics, diversity of designs used and the integration of sophisticated geometric patterns are also notable with arabesque.

\section{REFERENCES}

Afshar, Iraj 0.1374. Memory of Yazd, Tehran (c) 2. Association of cultural figures

Emami, S. 0.1381. Symbol and allegory, Vshbaht are differences. Book of the Month Art. 47-48: 6068.

Khademzadeh, M. Hasan 0.1374.Historical mosques in the city of Yazd. Tehran: Artistic and Cultural Heritage and Tourism

Danesh-Yazdi, Fatemeh. 1387. Yazd Islamic inscriptions. Tehran: Stari light Glory, glory 0.1376. Password thought and sacred art. Centeral Tehran

Hosseini, SeyedHashem and janitorial Abargouei, Hussein 0.1393. Analysis symbolic aspects Shiite mosque in Yazd decorations.Journal of theory.(29) JalaliJafari and called Bhdad.hmyd and 0.1391.in what looked like a brick with plaster management approach to the bottom of the Grand Mosque of Yazd. Fine-arts magazine. Volume 17, Number 4

Barati, Parinaz 0.1380. Self-knowledge by means of coded Adad.thrran: Siminsajadi, 1375. Ali shrine in the evolution of Islamic architecture from the beginning to the Mughal period. Tehran: Cultural Heritage and Tourism Organization

Tabatabai, Seyyed Muhammad 0.1363. Tafsir al-line translator Mohammad BagherMousavi 32.Hmdany.thran: New Said 